\title{
Continuamos Vivendo a Pandemia: novas angústias e desafios na educação médica brasileira
}

\section{We Continue Living the Pandemic: New Anxieties and Challenges in Brazilian Medical Education}

\author{
Nildo Alves Batista' @ | nabatista11@gmail.com \\ Sandro Schreiber de Oliveira² (1) sandro.schreiber@yahoo.com.br \\ Denise Herdy Afonso ${ }^{3}$ (1) deniseherdy@gmail.com \\ Eduardo Arquimino Postal ${ }^{4}$ (1) eduardo_postal@hotmail.com \\ Eliana Goldfarb Cyrino ${ }^{5}$ (1) ecyrino@fmb.unesp.br \\ André Ferreira de Abreu Júnior ${ }^{6}$ (1) andref.abreuj@gmail.com \\ Carlos Eduardo Merss 7 (1) merssmd@gmail.com
}

As crises demandam ações incisivas e provocam mudanças estruturais - isso já está posto. O que segue em aberto são as escolhas a serem tomadas, cujos efeitos serão sentidos não apenas agora, mas nos anos que virão (...). Uma sociedade em crise é convidada a repensar as necessidades que deseja priorizar.

Iniciamos 2021 com a percepção de que ainda continuamos vivendo a pandemia: muitos casos novos, muitos doentes, internações e mortes pela Covid - 19. Em consonância com a avaliação da imensa maioria das entidades científicas nacionais e internacionais - não sem angústia e tristeza - temos a certeza de que o Brasil perdeu importantes oportunidades de responder, com maior potência, aos desafios da pandemia. Assim, também iniciamos 2021 com a convicção de que precisávamos continuar a trazer a pandemia para o centro da educação médica - no Brasil - e nos debruçar sobre a realidade para entender os caminhos que estão sendo trilhados pelas escolas médicas, reconhecendo as dificuldades e os desafios em mais um ano de tragédia nacional e mundial.

Comprometido e motivado, o Conselho Diretor da ABEM compreendeu a necessidade de organizar um Debate Ampliado com a comunidade acadêmica para refletir sobre a educação médica neste momento. Melhores alternativas para o enfrentamento estariam disponíveis e teriam nos trazido melhor destino se adotadas com agilidade e constância por nossos governantes. Enfrentamos a negligência e o negacionismo de muitos entes públicos, a falta de vacinas para todos, a fragilidade do direcionamento de ações pelo Ministério da Saúde e da Educação e identificamos a dificuldade de articular e trocar experiências em âmbito nacional. Partimos do acúmulo alcançado pelo trabalho junto às escolas médicas desenvolvido - em 2020 - com ênfase no reconhecimento e valorização das ações possíveis realizadas pela comunidade acadêmica, visando ao enfrentamento, aprendizado e transformação da realidade. Se não com grandes avanços, pelo menos garantindo que não houvesse retrocessos.

Para iniciar os trabalhos do Debate Ampliado, optamos por buscar uma atualização do diagnóstico situacional realizado em 2020; para tal, enviamos, em maio de 2021, no formato on-line, um questionário dirigido à comunidade acadêmica, com questões abertas e fechadas que versavam sobre o ensino médico e o momento vivenciado pela pandemia. Obtivemos respostas de 277 docentes, 199 discentes e 46 gestores. A análise deste material nos mostrou não só o quanto as escolas precisam de apoio neste momento, bem como a intensidade e o impacto da pandemia para todos.

Com o objetivo de dialogar de forma síncrona com representantes da comunidade acadêmica, convidamos a participar do debate todas as escolas associadas da Abem com representação de docentes, discentes e gestores, além de 18 mediadores. Inscreveram-se 81 escolas, de todas as regionais da ABEM, por meio de seus representantes, conforme Figuras 1 e 2 .

\footnotetext{
1 Diretor Presidente da Associação Brasileira de Educação Médica, Brasília, Distrito Federal, Brasil.

2 Diretor Vice-Presidente da Associação Brasileira de Educação Médica, Brasília, Distrito Federal, Brasil.

${ }^{3}$ Diretora Tesoureira da Associação Brasileira de Educação Médica, Brasília, Distrito Federal, Brasil.

${ }^{4}$ Diretor Secretário da Associação Brasileira de Educação Médica, Brasília, Distrito Federal, Brasil.

${ }^{5}$ Diretora de Inovação da Associação Brasileira de Educação Médica, Brasília, Distrito Federal, Brasil.

${ }^{6}$ Diretor Médico Residente da Associação Brasileira de Educação Médica, Brasília, Distrito Federal, Brasil.

${ }^{7}$ Diretor Discente da Associação Brasileira de Educação Médica, Brasília, Distrito Federal, Brasil.
} 
Figura 1. Escolas inscritas no Debate Ampliado ABEM, segundo instituições de ensino superior, Brasil, 2021.

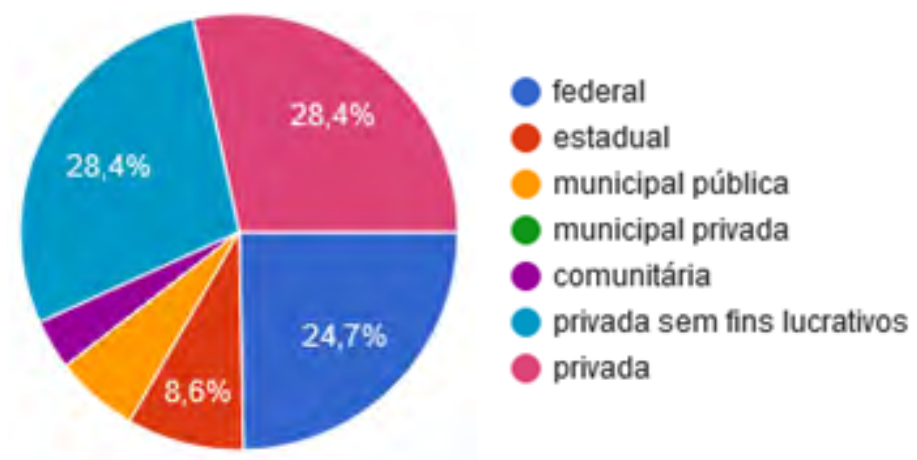

Assim, realizamos - no dia 29 de junho de 2021 - debates com a participação de 160 pessoas. Por meio de metodologia participativa, oficinas em pequenos grupos com produtos de relatoria e trabalho em plenárias, foi possível trocar e valorizar experiências de conquistas e desafios vivenciados neste momento. As temáticas desenvolvidas buscaram responder a questões voltadas aos diferentes períodos dos cursos, préinternato e internato.

Os grupos abordaram aspectos relativos ao momento de recepção de ingressantes nos cursos de medicina, à situação do ensino remoto ou híbrido nas escolas, às possibilidades de realização de atividades práticas, aos cenários destas práticas, à avaliação do estudante e à experiência com o uso de simulações. Além disso, discutiram antigos desafios como a integração ensino-serviço e seus diferentes estágios de implementação, bem como o dilema da antecipação da colação de grau frente aos processos de judicialização disseminados pelo país. Por fim, desenvolvemos o debate sobre a pertinência e dificuldade de garantir o acompanhamento institucional dos egressos dos cursos de medicina nestes anos de pandemia.

O encontro mostrou-se como um necessário e gratificante momento de trabalho, caracterizando-se pela solidariedade e partilha de experiências, angústias e incertezas. Permitiu também identificar o solitário caminho trilhado pelas
Figura 2. Escolas inscritas no Debate Ampliado ABEM, segundo regionais da $A B E M$, Brasil, 2021.

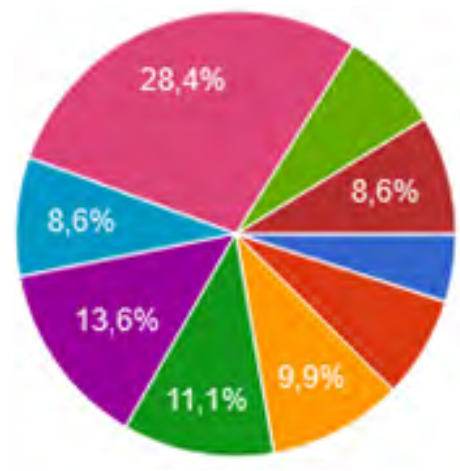

NORTE (Acre, Amapá, Amazonas, Pará, Rondônia, Roraima, Tocantins)

- NORDESTE 1 (Alagoas, Bahia, Sergi.. NORDESTE 2: (Ceará, Maranhão, Pa. MINAS GERAIS

- CENTRO OESTE: (Goiás, Mato Gros. RIO DE JANEIRO/ESPIRITO SANTO SÃO PAULO

SUL 1: (Rio Grande do Sul)

SUL 2: (Paraná, Santa Catarina)

escolas num contexto de orientações pouco precisas, por vezes conflitantes, ou mesmo inexistentes, por parte dos governantes. Identificamos que algumas escolas têm vivenciado a possibilidade de uma formação mais orgânica e comprometida com respostas à situação pandêmica, ampliando suas participações nas redes de atenção e no atendimento às demandas locais enquanto outras escolas têm apresentado maiores dificuldades para responder ao momento. Foram compartilhadas várias experiências originais e criativas, mas também muito sofrimento no cotidiano de discentes e docentes: sensação de isolamento, sobrecarga de trabalho e carência de encontros presenciais no ambiente das escolas.

A realização do debate evidenciou a importância da construção coletiva e coordenada. A ampliação de modos de escuta da realidade, gerando mobilização de todos, trouxe uma perspectiva da possibilidade de caminhos diversos, reafirmando as evidências relacionadas ao valor de estar juntos e a identificação de formas de apoio mútuo. $O$ debate evidenciou que não é possível propor soluções simples para a situação complexa pela qual passa a educação médica hoje em nosso país, carente de normativas certeiras, abandonada pelos seus dirigentes ministeriais, alvo cada vez mais frágil da massificação de uma educação com baixa qualidade, sem crítica e vazia de reflexão.

Figura 3. Nuvem de palavras representando as respostas sobre os desafios a serem enfrentados.

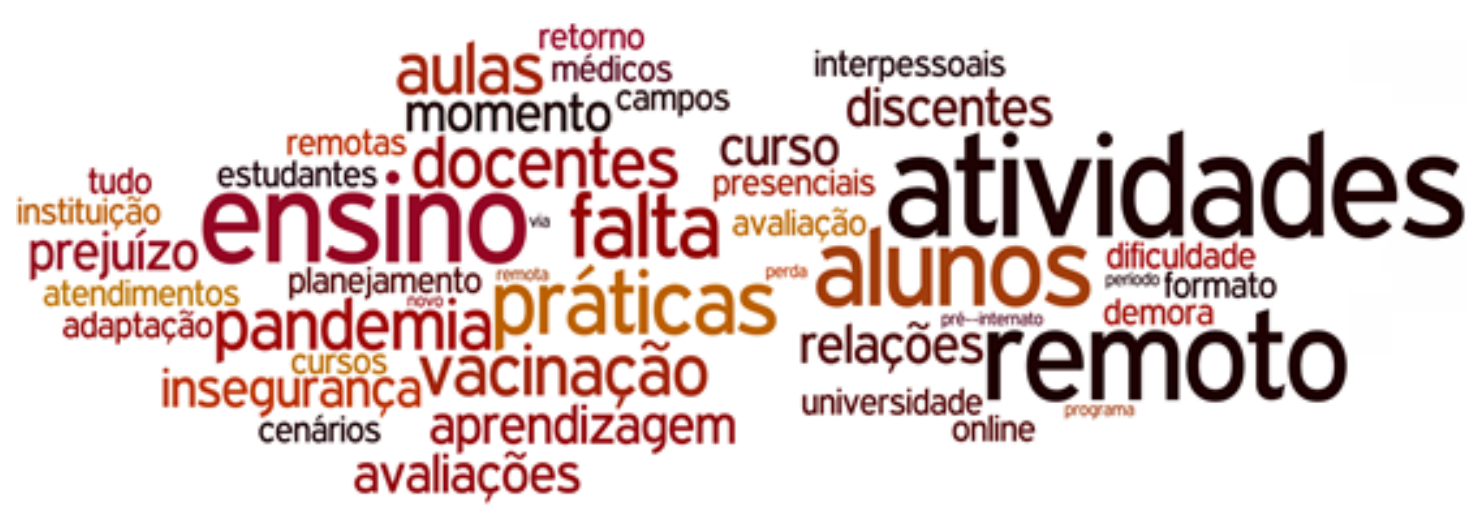


O Conselho Diretor - a partir desta experiência concretiza o compromisso da Abem com a liderança e coordenação deste debate e reafirma o seu papel como uma associação que zela pelas escolas, pela comunidade acadêmica e pela educação médica brasileira.

\section{CONTRIBUIÇÃO DOS AUTORES}

Os autores contribuíram igualmente para a elaboração do artigo.

\section{CONFLITO DE INTERESSES}

Os autores declaram não haver conflito de interesses.

\section{FINANCIAMENTO}

Os autores declaram não haver financiamento.

\section{REFERÊNCIA}

1. Isoni AT. Renda básica universal: um debate necessário. In: Tostes A, Melo Filho H. Quarentena: reflexões sobre a pandemia e depois. Bauru: Canal 6; 2020; p. 16. 